\title{
ПРЕДЕЛЬНЫЕ КОЭФФИЦИЕНТЫ АКТИВНОСТИ СПИРТОВ В ОРГАНИЧЕСКИХ РАСТВОРИТЕЛЯХ И ВОДЕ
}

\author{
(Представил Ю. Канн)
}

Спиртсодержащие жидкие системы широко используются в химической технологии и лазораторной практике. Поэтому знание их физикохимического поведения представляет не только теоретический, но и чисто прикладной интерес.

Цель настоящей работы - определение предельных коэффициентов активности некоторых незамещенных и хлорированных спиртов нормального и изостроения в различных органических растворителях и воде. Сделана также попытка установить эмпирическую связь между коэффициентами активности спиртов и физико-химическими характеристиками растворителей.

Такая постановка задачи вытекает из практической необходимости прогнозировать экстрагирующую способность экстрагентов по отношению к спиртам и оценить возможность разделения некоторых спиртсодержащих растворов дистилляцией. Кроме того, предельные коэффициенты активности являются одним из важнейших источников информации о характере процессов межмолекулярного взаимодействия молекул в жидком состоянии.

\section{Экспериментальная часть}

Коэффициенты активности спиртов в воде $\left(\gamma_{(W)}^{\infty}\right)$ (табл. 1) получили как произведение экспериментальных величин предельного коэффициента распределения между гексадеканом $H$ и водой $W\left(K_{(H / W)}^{\infty}\right)$ и предельного коэффициента активности в гексадекане $\left(\gamma_{(H)}^{\infty}\right)$ :

$$
\ln \gamma_{(W)}^{\infty}=\ln K_{(H / W)}^{\infty}+\ln \gamma_{(H)}^{\infty} .
$$

Предельные коэффициенты активности спиртов в гексадекане $(H)$ и воде (W) и их коэффициенты распределения между $H$ и $W$ (мол.доли/мол.доли) при $293 \mathrm{~K}$

\begin{tabular}{l|c|cc}
\hline \multicolumn{1}{c|}{ Соединение } & $\gamma_{(H)}^{\infty}$ & $\gamma_{(W)}^{\infty}$ & $K_{(H / W)}^{\infty}$ \\
\hline 1-Пропанол & & & 0,407 \\
2-Метил-1-пропанол & 32,1 & 13,1 & 1,67 \\
1-Бутанол & 28,0 & 46,8 & 1,40 \\
2-Бутанол & 32,9 & 46,1 & 1,04 \\
3-Метил-1-бутанол & 18,2 & 18,9 & 5,75 \\
1-Пентанол & 30,1 & 172,8 & 28,32 \\
1-Гексанол & 26,2 & 165,8 & 4,92 \\
Циклогексанол & 28,0 & 800,3 & 0,219 \\
2-Хлор-1-этанол & 13,6 & 66,9 & 1,46 \\
1,З-Дихлор-2-пропанол & 40,4 & 38,6 &
\end{tabular}


Значения $\gamma_{(H)}^{\infty}$ определяли методом ГЖХ в области $303-328 \mathrm{~K}$ по методике, описанной в [1]. Величины $\gamma_{(H)}^{\infty}$ при $293 \mathrm{~K}$ получили путем экстраполяции зависимости $\ln \gamma_{(H)}^{\infty}(T)$ от $1 / T$ к 293,15 K по уравнению

$$
\ln \gamma_{(H)}^{\infty}(T)=b_{0}+b_{1} \frac{T-298,15}{T}
$$

где $b_{0}$ и $b_{1}-$ эмпирические константы (численные величины их для различных спиртов приведены в [ㄹ]).

Предельные коэффициенты активности спиртов в органических растворителях $S\left(\gamma_{(\mathrm{S})}^{\infty}\right)$, не смешивающихся с водой, получили через $\gamma_{(W)}^{\infty}$ и экспериментальные значения коэффициентов распределения спирта между данным $S$ и водой $\left(K_{(S / W)}^{\infty}\right)$ :

$$
\ln \gamma_{(S)}^{\infty}=\ln \gamma_{(W)}^{\infty}-\ln K_{(S / W)}^{\infty}
$$

или

$$
\ln \gamma_{(S)}^{\infty}=\ln \left(K_{(H / W)}^{\infty} / K_{(S / W)}^{\infty}\right)+\ln \gamma_{(H)}^{\infty} .
$$

Методика определения этих величин более подробно описана в [ $\left.{ }^{2}\right]$.

Полученные результаты (табл. 2 и 3) показывают, что для растворов спиртов в неполярных растворителях характерна значительная положительная неидеальность $\left(\gamma^{\infty}>1\right)$, обусловленная затратой энергии на деполимеризацию спирта. Как правило, с ростом числа атомов углерода в молекуле спирта неидеальность растворов закономерно уменьшается. Это же явление наблюдается при перемещении ОН-группы ближе к центру молекулы.

\begin{tabular}{|c|c|c|c|c|c|}
\hline Растворитель & $\begin{array}{c}\text { 1-Пропа- } \\
\text { нол }\end{array}$ & $\begin{array}{c}\text { 1-Бута- } \\
\text { нол }\end{array}$ & $\begin{array}{c}\text { 2-Бута- } \\
\text { нол }\end{array}$ & $\begin{array}{c}\text { 1-Пента- } \\
\text { нол }\end{array}$ & $\begin{array}{c}\text { 1-Гекса- } \\
\text { нол }\end{array}$ \\
\hline Гексан & - & 46,6 & 21,4 & 34,6 & 37,1 \\
\hline Гептан & 55,3 & 43,1 & 20,3 & 36,4 & 37,6 \\
\hline Октан & 34,6 & 40,4 & 20,9 & 34,0 & 39,7 \\
\hline Декан & 28,1 & 34,9 & 18,3 & 29,4 & 29,7 \\
\hline Циклогексан & - & - & 19,1 & 33,4 & 36,0 \\
\hline Бензол & 11,5 & - & 7,81 & 9,77 & 9,98 \\
\hline Толуол & 11,6 & 12,0 & 8,04 & & 9,54 \\
\hline$o$-Ксилол & 18,1 & 12,7 & 7,68 & 10,0 & 9,57 \\
\hline м-Ксилол & 24,4 & 14,5 & 8,21 & 9,70 & - \\
\hline$n$-Ксилол & 13,9 & 22,0 & 6,92 & 9,58 & - \\
\hline Этилбензол & 9,58 & 13,7 & 8,58 & 10,4 & - \\
\hline Тетрахлорметан & 24,4 & - & 11,4 & 15,8 & 16,9 \\
\hline Хлоргексан & 12,3 & 10,5 & 5,81 & 8,55 & - \\
\hline Хлороктан & 13,1 & 15,9 & 7,74 & 10,9 & 11,8 \\
\hline Хлорбензол & 13,9 & 11,9 & 8,40 & 9,15 & - \\
\hline Бромоктан & 17,5 & 13,4 & 7,19 & 10,1 & 12,2 \\
\hline Бромбензол & 18,0 & 13,3 & 9,69 & 10,1 & 11,1 \\
\hline 1-Октанол & 0,901 & 0,867 & 0,665 & 0,742 & 0,812 \\
\hline 1-Нонанол & 0,975 & 0,923 & 0,565 & 0,807 & 0,891 \\
\hline 1-Деканол & 0,953 & 0,906 & 0,680 & 0,813 & 0,927 \\
\hline Анизол & 7,38 & 7,92 & 5,90 & 6,67 & 7,32 \\
\hline Бутилфениловый эфир & 4,58 & 7,28 & 3,81 & 4,31 & 5,41 \\
\hline Бутилацетат & 2,81 & - & 2,29 & 1,95 & 2,17 \\
\hline Дибутилфталат & 3,23 & - & 2,00 & 2,28 & 2,90 \\
\hline 2-Октанон & 1,96 & 1,90 & 1,65 & 1,65 & 1,84 \\
\hline Нитробензол & 10,4 & 9,88 & 6,25 & 8,66 & 9,48 \\
\hline
\end{tabular}

Предельные коэффициенты активности спиртов нормального строения при $293 \mathrm{~K}$ 
Предельные коэффициенты активности разветвленных и хлорированных спиртов при $293 \mathrm{~K}$

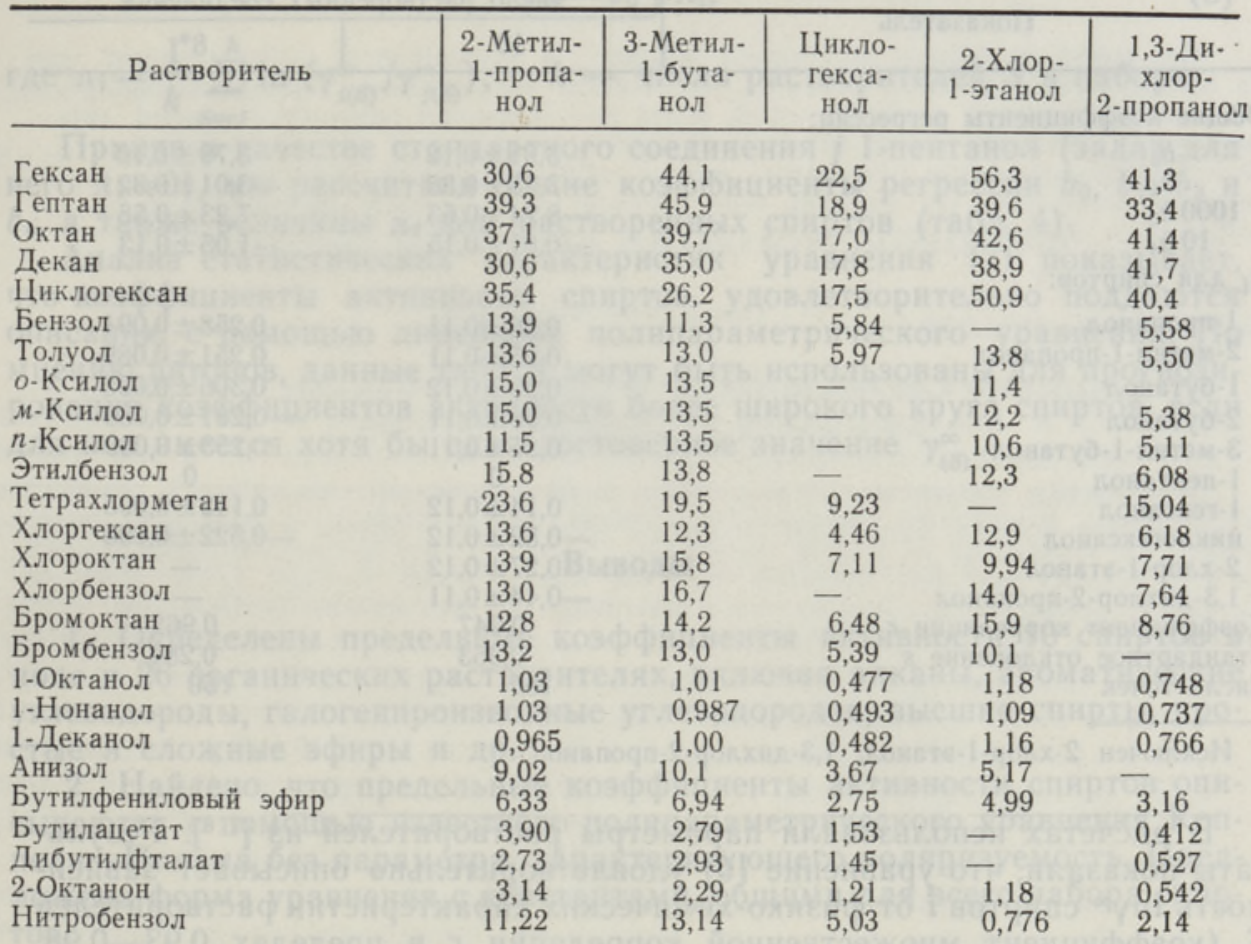

В полярных растворителях, склонных к образованию со спиртами Н-связи (кетоны, простые и сложные эфиры), величины $\gamma_{(\mathrm{S})}^{\infty}$ намного ниже, чем в неполярных, но все же выше единицы. Это значит, что энергия, расходуемая на деполимеризацию спирта, не компенсируется за счет энергии образования Н-связи между молекулами спирта и растворителя. Только растворы в высших спиртах близки к идеальным.

\section{Связь между предельными коэффициентами активности и физико- химическими характеристиками растворителей}

Экспериментальный материал о коэффициентах активности использовали для установления эмпирической связи между $\gamma^{\infty}$ и характеристиками $X$ чистых растворителей. За основу принимали известное полипараметрическое уравнение Коппеля-Пальма. Это уравнение в виде

$$
\ln \gamma^{\infty}=b_{0}+\sum_{p=1}^{m} b_{p} X_{p}
$$

неоднократно (напр., $\left.\left[{ }^{3-6}\right]\right)$ использовалось при описании термодинамического поведения растворов в зависимости от полярности $Y(Y \equiv(\varepsilon-1) /$ $(2 \varepsilon+1)$, где $\varepsilon$ - диэлектрическая постоянная), поляризуемости $P$ $\left(P \equiv\left(n^{2}-1\right) /\left(n^{2}+2\right)\right.$, где $n-$ показатель преломления $\left.n_{D}^{20}\right)$; электрофильности $E$ и нуклеофильности $B$ растворителя или растворенного соединения ( $p$ - номер параметра, $m$ - общее число параметров).

Для данного соедннения $i$ в наборе растворителей $S$ уравнение имеет вид

$$
\ln \gamma_{i(\mathrm{~S})}^{\infty}=b_{0 i}+b_{1 i} Y_{\mathrm{S}}+b_{2 i} P_{\mathrm{S}}+b_{3 i} E_{\mathrm{S}}+b_{4 i} B_{\mathrm{S}}
$$


Коэффициенты регрессии и значения $\pi_{i}$ уравнения (7)

\begin{tabular}{c|c|c}
\hline \multirow{2}{*}{ Показатель } & Число растворенных соединений \\
\cline { 2 - 3 } & 10 & $8^{*}$ \\
\hline
\end{tabular}

Общие коэффициенты регрессии:

$$
\begin{array}{r}
b_{0} \\
b_{1} \\
1000 b_{3} \\
10 b_{4}
\end{array}
$$

$\pi_{i}$ для спиртов:

1-пропанол

2-метил-1-пропанол

1-бутанол

2-бутанол

3-метил-1-бутанол

1 -пентанол

1-гексанол

циклогексанол

2-хлор-1-этанол

1,3-дихлор-2-пропанол

Коэффициент корреляции $r$

Стандартное отклонение $s$

Число точек

$$
\begin{array}{r}
3,91 \pm 0,12 \\
-3,28 \pm 0,36 \\
-8,24 \pm 0,63 \\
-0,81 \pm 0,15 \\
\\
0,26 \pm 0,11 \\
0,25 \pm 0,11 \\
0,29 \pm 0,12 \\
-0,28 \pm 0,11 \\
0,25 \pm 0,11 \\
0 \\
0,14 \pm 0,12 \\
-0,52 \pm 0,12 \\
0,27 \pm 0,12 \\
-0,44 \pm 0,11 \\
0,947 \\
0,353 \\
185
\end{array}
$$

$3,79 \pm 0,10$

$-3,01 \pm 0,32$

$-7,23 \pm 0,55$

$-1,05 \pm 0,13$

$0,258 \pm 0,091$

$0,251 \pm 0,089$

$0,306 \pm 0,095$

$-0,281 \pm 0,089$

$0,253 \pm 0,089$

0

$0,142 \pm 0,095$

$-0,522 \pm 0,095$

$0, \overline{\bar{C}} 2$
0,284
150

* Исключен 2-хлор-1-этанол, 1,3-дихлор-2-пропанол.

В расчетах использовали параметры растворителей из $\left[{ }^{7,8}\right]$. Результаты показали, что уравнение (6) удовлетворительно описывает зависимость $\ln \gamma^{\infty}$ спиртов $i$ от физико-химических характеристик растворителей $S$ (коэффициент множественной корреляции $r$ в пределах $0,93-0,98$, стандартное отклонение $s$ величин $\ln \gamma_{i(S)}^{\infty} 0,24-0,40$, т. е. $5-8 \%$ от интервала варьирования $\left.\ln \gamma_{i(S)}^{\infty}\right)$.

Однако при оценке влияния отдельных входных параметров на $\ln \gamma_{i(S)}^{\infty}$ выяснилось, что коэффициенты частной корреляции $\left(r_{y \mathrm{x}}\right)$, характеризующие связь между $\ln \gamma_{i(S)}^{\infty}$ и $P_{S}$ растворителей, невысоки. Доверительный интервал коэффициентов $b_{2 i}$ по сравнению с их собственными величинами оказался значительным. Поэтому параметр $P_{S}$ можно исключить из уравнения (6) без существенного ухудшения его статистической достоверности.

Такой вывод можно считать вполне закономерным, так как параметры $Y$ и $P$ описываются с помощью подобных эмпирических уравнений и близки по физическому смыслу [ $\left.{ }^{9}\right]$.

Коэффициенты частной корреляции $r_{y x}$ при исключении параметра $P$ показывают, что наиболее сильная взаимосвязь наблюдается между $\ln \gamma_{i(S)}^{\infty}$ и нуклеофильностью $B_{S}\left(r_{y x}\right.$ около 0,9$)$. Почти одинаковый $r_{y x}($ порядка 0,7$)$ имеется между $\ln \gamma_{i(S)}^{\infty}$ и $Y_{S}$ или между $\ln \gamma_{i(S)}^{\infty}$ и $E_{S}$. При этом характерно, что с ростом числа атомов углерода в молекуле спирта $r_{y x}$ между $\ln \gamma_{i(S)}^{\infty}$ и $Y_{S}$ имеет тенденцию к увелнчению (в случае 1 -пропанола $r_{y x}$ равен 0,69 , в случае 1 -гексанола $\left.-0,81\right)$.

Сравнение коэффициентов регрессии $b_{1 i}, b_{3 i}$ и $b_{4 i}$ (при исключении члена $\left.b_{2 i} P_{S}^{*}\right)$ показывает, что в пределах доверительны: інтервалов соответствующие величины для всех изученных спиртов практически совпадают. Это дает возможность описывать зависимость $\ln \gamma_{i(\mathrm{~S})}^{\infty}$ от характеристик растворителя с помощью общего регрессионного уравнения, аналогичного предложенному в $\left[{ }^{2}\right]$ :

$$
\ln \gamma_{i(\mathrm{~S})}^{\infty}=b_{0}+b_{1} Y_{\mathrm{S}}+b_{3} E_{\mathrm{S}}+b_{4} B_{\mathrm{S}}+\pi_{i}
$$


где член $b_{0 i}$ для данного соединения $i$ в ура̄внении (7) заменен суммой общей $\left(b_{0}\right)$ и «характеристической» $\left(\pi_{i}\right)$ частей:

$$
b_{0 i}=b_{0}+\pi_{i}
$$

где $\pi_{i}=\frac{1}{k} \sum_{S=1}^{k} \ln \left(\gamma_{i(S)}^{\infty} / \gamma_{j(S)}^{\infty}\right), \quad k-$ число растворителей $S$ в наборе.

Приняв в качестве стандартного соединения $j$ 1-пентанол (задав для него $\left.\pi_{i}=0\right)$, мы рассчитали общие коэффициенты регрессии $b_{0}, b_{1}, b_{3}$ и $b_{4}$, а также величины $\pi_{i}$ для растворенных спиртов (табл. 4).

Анализ статистических характеристик уравнения (7) показывает, что коэффициенты активности спиртов удовлетворительно поддаются описанию с помощью линейного полипараметрического уравнения. По мнению авторов, данные табл. 4 могут быть использованы для прогнозирования коэффициентов активности более широкого круга спиртов, если для них имеется хотя бы одно достоверное значение $\gamma_{(S)}^{\infty}$.

\section{Выводы}

1. Определены предельные коэффициенты активности 10 спиртов в воде и 26 органических растворителях, включая алканы, ароматические углеводороды, галогенпроизводные углеводородов, высшие спирты, простые и сложные эфиры и др.

2. Найдено, что предельные коэффициенты активности спиртов описываются с помощью известного полипараметрического уравнения Коппеля-Пальма без параметра, характеризующего поляризуемость. Предложена форма уравнения с константами, общими для всего набора спиртов.

\section{Л И ТЕ РА Т У РА}

1. Нгнат А., Мельдер Л. Некоторые закономерности распределения спиртов между фазами органического растворителя и воды // Изв. АН ЭССР. Хим., 1985, 34, № $1,63-68$.

2. Игнат А. В., Мельдер Л. И. Предельные коэффициенты активности спиртов в гексадекане // Ж. прикл. хим., 1985, 58, № 12, 2747-2749.

3. Макитра Р. Г., Пириг Я. Н. Применение линейных уравнений, включающих несколько параметров, для характеристики селективности растворителей при экстракции углеводородов // Нефтехимня, 1980, 20, № 1, 145-154.

4. Макитра Р. Г., Мельдер Л. И., Пириг Я. Н., Эббер А. В. Корреляция предельных коэффициентов активности сложных эфиров и кетонов с характеристиками растворителей // Укр. хим. ж., 1983, 49, вып. 4, 367-372.

5. Брик Д. В., Макитра Р. Г., Пириг Я. Н., Стефанык Ю. В. Влияние свойств растворнтелей на растворимость кислорода // Ж. прикл. хим., 1988, 59, № 1, 91-97.

6. Мельдер Л. И., Кирьянен Э. И., Тамвелиус Х. Я. Взаимосвязь предельных коэффициентов активности органических соединений в фенолах с их физнко-хнмическими характеристиками и структурой растворителя // Горючие сланцы, 1986, 3, № $1,93-100$.

7. Коппель И. А., Паю А. И. Параметры общей основности растворителей // Реакционная способность органических соединеннй, 1974, 11, № 1/39, 121-138.

8. Коппель И. А., Паю А. И. Расширенная шкала параметров органических соединений // Реакционная способность органических соединений, 1974, 11, № 1/39, 138143.

9. Пальм В. А. Основы количественной теории органических реакций. Л., 1977.
Ннститут химии
Академии наук Эстонской ССР
Поступила в редакцию 5/VII 1988 


\section{ALKOHOLIDE AKTIIVSUSTEGURID ORGAANILISTES LAHUSTITES JA VEES LOPMATUL LAHJENDUSEL}

On määratud kümne asendamata alkoholi ja kloroalkoholi aktiivsustegurid vees ja 26 orgaanilises lahustis (alkaanid, aromaatsed süsivesinikud, süsivesinike halogeenderivaadid, kōrgemad alkoholid, eetrid, estrid jm.). Lõpmatul lahjendusel saadud aktiivsustegurite sõltuvust lahusti füüsikalis-keemilistest omadustest on kirjeldatud KoppeliPalmi polüparameetrilise võrrandiga, millest võib elimineerida polariseeritavust iseloomustava parameetri. On esitatud selle võrrandi erikuju, mille konstandid on uuritud alkoholidele ühised.

\section{A. IGNAT, L. MÖLDER}

\section{THE ACTIVITY COEFFICIENTS OF ALCOHOLS IN ORGANIC SOLVENTS AND WATER AT INFINITE DILUTION}

The activity coefficients of 10 alcohols in 26 organic solvents (alkanes, aromatic hydrocarbons, halogenated hydrocarbons, alcohols, ethers, esters, a.o.) have been determined. The dependence of activity coefficients on various physico-chemical characteristics of pure solvents has been described with the Koppel-Palm multiple linear equation excluding polarizability. The equation describing all the systems studied has been derived. 